\title{
Health Behaviour of Higher Education Employees - Value-Transmitting Conduct of Professionals to their Students
}

\author{
Veronika MÁTó ${ }^{1}$, Klára TARKó ${ }^{1}$, Krisztina TóTH², \\ László NagymajténYI3, Edit PauliK3 \\ mveronika@jgypk.szte.hu, tarko@jgypk.szte.hu, \\ ktoth@tba21.hu, nagymajtenyi.laszlo@med.u-szeged.hu, \\ paulik.edit@med.u-szeged.hu \\ ('University of Szeged, Juhász Gyula Faculty of Education, \\ Institute of Applied Health Sciences and Health Promotion, \\ Szeged, Hungary, ${ }^{2}$ Hungarian Academy of Sciences \& University \\ of Szeged, Research Group on Artificial Intelligence, Szeged, \\ Hungary, 3Department of Public Health, Faculty of Medicine, \\ University of Szeged, Szeged, Hungary)
}

Received: 06.06.2016; Accepted: 21.08.2016

\begin{abstract}
Workplaces and employees' health are closely connected. A healthy workforce would increase productivity, effectivity and efficiency which will benefit the employer in financial and moral terms as well. On the contrary, if employees experience stress, long working hours, bad managerial style, not safe working conditions that would lead to ill physical and mental health and poor lifestyle habits like lack of exercises, smoking, drinking and inadequate diets. Our research was carried out at faculties of the University of Szeged ( $n=261)$. Data acquisition was online, with the help of a self-completed questionnaire distributed through $e$ mail. Apart from basic socio-demographic data the questionnaire contained questions referring to employees' nutrition-, exercising-, sporting-, and leisure habits, visiting the doctor and their smoking-and alcohol consumption frequency. To sum all findings up, we can say that employees of the University of Szeged are concerned about their health and act for preserving and promoting it. They strive at creating a good well-being. Their health behaviour is acceptable and can mean a suitable example for the young adult generation.
\end{abstract}

Keywords: health behaviour, higher education, lifestyle, health status 


\section{Introduction}

Workplaces and employees' health are closely connected. A healthy workforce would increase productivity, effectivity and efficiency which will benefit the employer in financial and moral terms as well. On the contrary, if employees experience stress, long working hours, bad managerial style, not safe working conditions that would lead to ill physical and mental health and poor lifestyle habits like lack of exercises, smoking, drinking and inadequate diets (Sparks, Faragher \& Cooper, 2001).

Kouvonen et al. (2005) found clear evidence for the association between work stress and smoking, regardless of age, level of education, occupational status, marital status or type of employment. The higher the work stress is, the higher the smoking intensity becomes. Fichtenberg and Glantz (2006) suggest that workplaces should be smoke free, as evidence shows smoke-free workplaces help smokers quit smoking as well as prevent non-smokers from the dangers of passive smoking.

We can find different health behaviour patterns along socio-economic (SES) differences. This effect is proven, among others, in case of leisure time physical activity (Lindström, Hanson \& Östergren, 2001). Lindström et al. (2001) based their measure of SES on job title, tasks and position at work. In their studies, higher SES people were prevented from exercising by internal barriers (lack of motivation and leisure time) rather than by lack of money or existing disability reported by lower SES people. Linder (2009) researched the exercising behaviour of higher education employees. Employees reported on the mental, emotional appearance and weigh management benefits of exercising, while they experienced the disadvantages of lack of time and employer support, lack of health education, and home duties. The type of exercise higher education employees engaged in the most was walking.

The above differences might be due to differences in social capital, which according to Bourdieu's theory (1986) is also an indicator of our SES. High levels of social capital measured in dimensions like social support, social networks and participation is strongly associated with all components of health and health behaviour (Nieminen, 2015). Social participation is indicated by the number of social groups we belong to; social support is provided by all those people and groups we can rely on when we need help; social networks can promote our self-esteem and provide relief in stressful situations. According to Antonovsky's theory on the sense of coherence (in Nieminen, 2015) our social capital serves as a general resistance resource facilitating effective coping. Social capital and level of education go hand in hand. Ross and Wu (1995) stated, that education has a direct effect on health as well as indirect effects "through work and economic conditions, social-psychological resources and healthy lifestyle" (Ross \& Wu, 1995:719). The well-educated tend to have greater control over their lifestyle, like less smoking and drinking, more exercising, more health check-ups. Li and Powdthavee (2015) though say that education does not necessarily lead to the avoidance of smoking, drinking and engaging in more preventive health checks.

Kulhánová et al. (2014) conducted a study involving 21 European countries and showed that higher educational attainment leads to 
favourable trends in mortality, though the strength of this effect varies by countries. The effect of education on mortality was maximal in case of Hungarians. Increasing the level of education is a possible strategy to improve population health.

University as a workplace has all the prerequisites that can be utilized to become an effective intervention site: peer networks, time spent together with fellow workers (Hutchinson and Wilson, 2011), supporting academic environment, high level of education, knowledge and motivation. It is worth studying how a workplace like this affects its employees' health and health behaviour (Mátó, Nagymajtényi \& Paulik, 2015).

We can also state, that higher education employees' health and health behaviour are also closely connected to their 'clients' health. As an educational setting, higher education has the social commitment of creating a sense of responsibility towards health, a capacity to act and a health-conscious behaviour among students. "...health conscious persons are characterized as actively incorporating healthy behaviours in their daily routines, consistently being attentive to their health conditions, actively seeking and using health information from diverse sources, taking responsibility for their health, and being motivated to stay healthy" (Hong, 2009:7). Gardner (2015) argues, that automatization is a key element for making health behaviour a habit pervading our everyday activities. Educators in higher education, with their preferably automatized health conscious behaviour, could be the sources of setting examples for the growing generations (Lumpkin, 2008), and they could be role models through respect, admiration and imitation (Paice et al., 2005). Role-models could be those individuals whose behaviour is an example or a model for others, who want to learn these (Filstad et al., 2007). Certain professional values, attitudes, forms of behaviour (Paice et al., 2005), success in sciences and professional career (Perry \& Nixon, 2005) can also be examples. This way the health status and lifestyle of Higher Education professionals affect university students, hence they influence their students' health behaviour through their behaviour, habits and customs.

We have found it very important to study the health behaviour of employee working in higher education. Those, who work for the University of Szeged cooperate with young adults every day, aiding their effective knowledge acquisition, while at the same time forming students' health behaviour through the example of their own behaviour and habits. Higher education institutes this way have a direct influence on the lifestyle and health of their members. In the present paper we will study the range of health-influencing personal resources of Health Education professionals working at the University of Szeged.

\section{Research methods and sample}

Our research was carried out at faculties of the University of Szeged. Data acquisition was online, with the help of a self-completed questionnaire distributed through e-mail. Apart from basic socio-demographic data the questionnaire contained questions referring to employees' nutrition-, 
exercising-, sporting-, and leisure habits, visiting the doctor and their smoking- and alcohol consumption frequency.

Sample size was 261 employees, from 11 faculties out of the 12 ones at the University of Szeged. The sample composed of 33.0\% male and 67.0\% female participants. The mean age was 43.4 years, with the age range of 21-72 years. The respondents lived mainly in County - Csongrád (95.0\%), where the University is located. The rest lived in other counties, like Pest (2.3\%), Bács-Kiskun (1.5\%), Békés (o.8\%) and Jász-Nagykun-Szolnok (0.4\%). Szeged was their permanent residence in $74.7 \%, 13.8 \%$ commuted daily between their home and workplace, while 11.5\% had Szeged as their temporary place of residence. Participants lived mainly in family houses (37.2\%) or in apartment houses (42.9\%). More, than half of the sample was married or lived in partnership (69.8\%), while $17.2 \%$ were single, $11.9 \%$ divorced and $1.1 \%$ widow. $54.4 \%$ had one or two children, $15.3 \%$ had three or more children, while $30.3 \%$ had no children.

$47.9 \%$ of the answerers had a college or university degree, 40.6\%had a $\mathrm{PhD}$, and 5 people (1.9\%) were doctors of Academy. Secondary education alone was only of low frequency (9.5\%).

At the time of data acquisition participants (except for 5 people) were active workers (98.1\%), 86.6\% working as underling employees, while $11.5 \%$ worked in managerial positions.

Data analyses were performed using IBM SPSS 22.0. Simple descriptive statistics (frequencies, means $\pm \mathrm{SD}$ ), cross-tabulations with chi-square tests and Spearman correlations, t-probe were applied. Results were considered to be significant at $\mathrm{p}<0.05$.

The Regional and Institutional Human Medical Biological Research Ethics Committee of the Szent-Györgyi Albert Clinical Centre, University of Szeged approved the study protocol (No. 175/2012). Participation at the research was voluntary and anonymous.

\section{Results}

Firstly, we will analyse the health behaviour habits of the complete sample. Then we will highlight at the connection between participants' satisfaction with their own fitness, health and looks with the importance of health and with their self-categorised health status.

\section{Health behaviour habits}

Participants considered the preservation and protection of their own health very important. On a scale of 10 - where 10 meant 'very important' - the mean choice was $9.2(\mathrm{SD}=1.17)$.

More than half of the sample (60.5\%) reported they had a family member who was extremely conscious about the health of all members. This person was either the respondent (43.2\%), or his/her spouse/partner $(36.8 \%)$. In some cases, it was the child or the parent who considered health protection of family members as his/her job. 
A considerable percentage of participants had knowledge about health, health protection and healthy behaviour (96.6\%). 43.3\% of the sample obtained this knowledge through their profession, 53.3\% learnt them because they were interested in them. Health behaviour was further analysed along the following subdomains: health damaging behaviour, nutrition, exercising, leisure, holidays and screening.

\section{Health damaging behaviour}

It should be highlighted, that $13.9 \%$ of the complete sample was still smoking. 8.5\% of the employees smoked daily. Almost one third of all the answerers (29.7\%) smoked daily for a year long period, but they quitted. Those who once smoked and/or were still smoking started to smoke regularly at the average age of 18.5 years $(\mathrm{SD}=2.71) .63,2 \%$ of those workers who were still regular smokers smoked 1-10 cigarettes a day, and some of them smoked 11-20 cigarettes a day.

$13.9 \%$ of the complete sample did not drink alcohol, while $40.4 \%$ drank alcohol only at feasts or during visits. $16.6 \%$ drank $2-3$ times a month, and $16.6 \%$ drank a small amount several times a month. Only 5 answerers (2.2\%) reported on drinking a small amount of alcohol daily or several times a day.

\section{Nutrition}

It is preferential that most of the employees ate at least three times a day (Table 1). The ideal frequency of eating five times a day was very rare. They ate snacks rarely $(47.9 \%)$ or several times a week $(32.3 \%)$, but there were also some employees snacking every day (13.8\%).

Table 1. Employees' eating frequency (\%)

\begin{tabular}{|l|c|c|c|c|}
\hline Eating & daily & several times a week & rarely & never \\
\hline Breakfast & $\mathbf{7 9 . 3}$ & 7.4 & 12.4 & 0.9 \\
\hline Brunch & 19.4 & 17.1 & $\mathbf{3 6 . 4}$ & 27.2 \\
\hline Lunch & $\mathbf{7 4 . 7}$ & 17.5 & 6.9 & 0.9 \\
\hline Afternoon snack & 12.4 & 19.8 & $\mathbf{4 2 . 4}$ & 25.3 \\
\hline Dinner & $\mathbf{8 2 . 0}$ & 12.9 & 4.1 & 0.9 \\
\hline $\begin{array}{l}\text { Snacking when } \\
\text { not hungry }\end{array}$ & 13.8 & $\mathbf{3 2 . 3}$ & $\mathbf{4 7 . 9}$ & 6.0 \\
\hline
\end{tabular}

Apart from eating frequency the content of meals is also important. It is a positive result that drinking tap water and mineral water several times a day or daily was the most preferred way of hydration. When studying the frequency of eating food with carbohydrate content we found, that the answerers preferred white bread, though brown bread - which is a significant source of fibre - was also present in their nutrition at least couple of times a week. It is unfortunate that only a trifling proportion of the staff members ate raw vegetables (11.1\%) and raw fruits (18.9\%) several times a day. Milk with different fat content was consumed daily or several times a day only by $40.1 \%$ of the answerers. Respondents preferred lean 
pork meat and skinless chicken meat to more greasy kinds of meat, and light cold meat to their fattier versions. Respondents cooked primarily with sunflower oil (63\%), 22.7\% used olive- or canola oil. 5.6\% chose coconut fat or oil, $7.4 \%$ preferred animal fat, while only a few cases were reported when they cooked with margarine and butter. Part of healthy nutrition in adulthood is to prepare and eat our meals with less salt, and try to savour it with seasons. More than the half of respondents (61.8\%) used salt only when cooking, while $32.7 \%$ preferred less salty or unsalted food, meal. Only a low percent of respondents (5.5\%) ate salty or put extra salt into the ready meal. Most of the respondents did not choose an alternative form of nutrition (93.1\%). There were some semi-vegetarians (2.8\%) and some applying reform nutrition (2.3\%). Only $6.9 \%$ of respondents followed a fashionable diet for losing weight. 12 of them (80.0\%) ate vitamin and mineral products regularly. When studying the whole sample, $64.5 \%$ ate vitamin and/or mineral products regularly. Those who ate these products chose primarily combined vitamin and mineral products (40.1\%), and only vitamin products on the second place (21.2\%).

\section{Exercising}

$78.2 \%$ of respondents performed some kinds of physical exercises. Into physical exercise we included active walking, jogging and cycling performed at least once a week also. Respondents performed exercises 1-2 days a week (33.7\%), 3-4 days a week (22.1\%), 5 days a week (20.0\%), or daily (24.2\%). 44.8\% of respondents were doing sports. $12.7 \%$ of the asked workers did not perform any exercises or sports. Sports were performed generally several times a week (79.4\%), often twice a week (32.0\%), or three-four times (30.9\%). The reason behind doing sports was not because their friends or child/children suggested it (Figure 1), but primarily because of becoming healthy (90.8\%), and secondly because of creating a good well-being (66.3\%). A characteristic reason was to do sports out of pleasure $(57.1 \%)$ or to become fit $(53.1 \%)$ or to look good (48.0\%). In nine cases (9.2\%) the doctor suggested the respondent to do sports.

Figure 1. Reasons behind doing sports (\%)

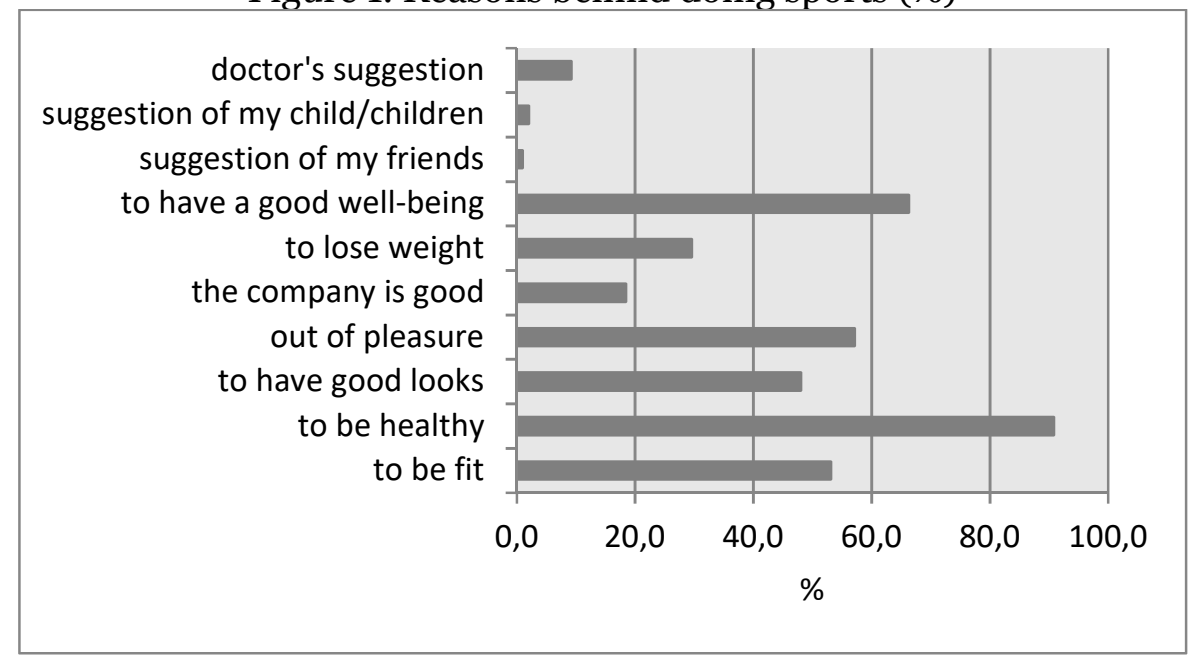




\section{Leisure time}

Respondent members of the university staff did work related tasks at home or in their workplaces, an average of 2.5 hours even on an ordinary day off. They slept 8 hours on an ordinary day off, spent 6-6.5 hours working on work-related plus household chores, and 4-4.5 hours with active leisure. The number of hours spent on leisure activities was favourable among the respondents.

Respondents spent their leisure time mainly with reading, discussions, visiting others, cooking and baking, walking, watching TV, listening to music, going for excursions, gardening or doing sports (Table 2).

Table 2. Activities the university staff spend their leisure time with (\%)

\begin{tabular}{|c|c|c|c|c|c|}
\hline Activity & $\%$ & Activity & $\%$ & Activity & $\%$ \\
\hline $\begin{array}{l}\text { visit places of } \\
\text { amusement }\end{array}$ & 9.0 & sport & 28.7 & reading & 73.1 \\
\hline listening to music & 37.2 & gardening & 36.3 & cooking, baking & 54.3 \\
\hline playing music & 9.0 & do it yourself & 11.7 & walking & 48.4 \\
\hline watching TV & 43.5 & handcraft & 13.9 & excursion & 37.2 \\
\hline cinema & 13.0 & $\begin{array}{l}\text { chess, cards, } \\
\text { bridge, board } \\
\text { games }\end{array}$ & 10.3 & hunting & 1.4 \\
\hline theatre, concert & 20.6 & billiard, bowling & 2.7 & grandchild & 1.4 \\
\hline $\begin{array}{l}\text { discussions, } \\
\text { visiting }\end{array}$ & 62.8 & other games & 13.5 & $\begin{array}{l}\text { language } \\
\text { learning }\end{array}$ & 1.4 \\
\hline
\end{tabular}

In an average weekday, they had almost 2 hours (mean=1.84, $\mathrm{SD}=1.29)$ to spend on leisure activities. Only $5.4 \%$ of respondents declared they did not have time for leisure during weekdays. This weekday leisure time was spent mainly at home, or with friends, or in cultural facilities, and there were also some employees visiting relatives or going to sport facilities (Figure 2). Almost one-third of respondents spent this time with browsing the Internet, skype or watching films on-line. There were only a few people who spent their leisure time in a club or in a community centre during weekdays.

There were also some staff members (2.7\%) who did not have any time for leisure during weekends. During the weekends leisure time was spent mostly with friends and relatives, or at cultural facilities, shopping centres, or cinema. 
Figure 2. Ways of spending leisure time during the week and in the weekends (\%)

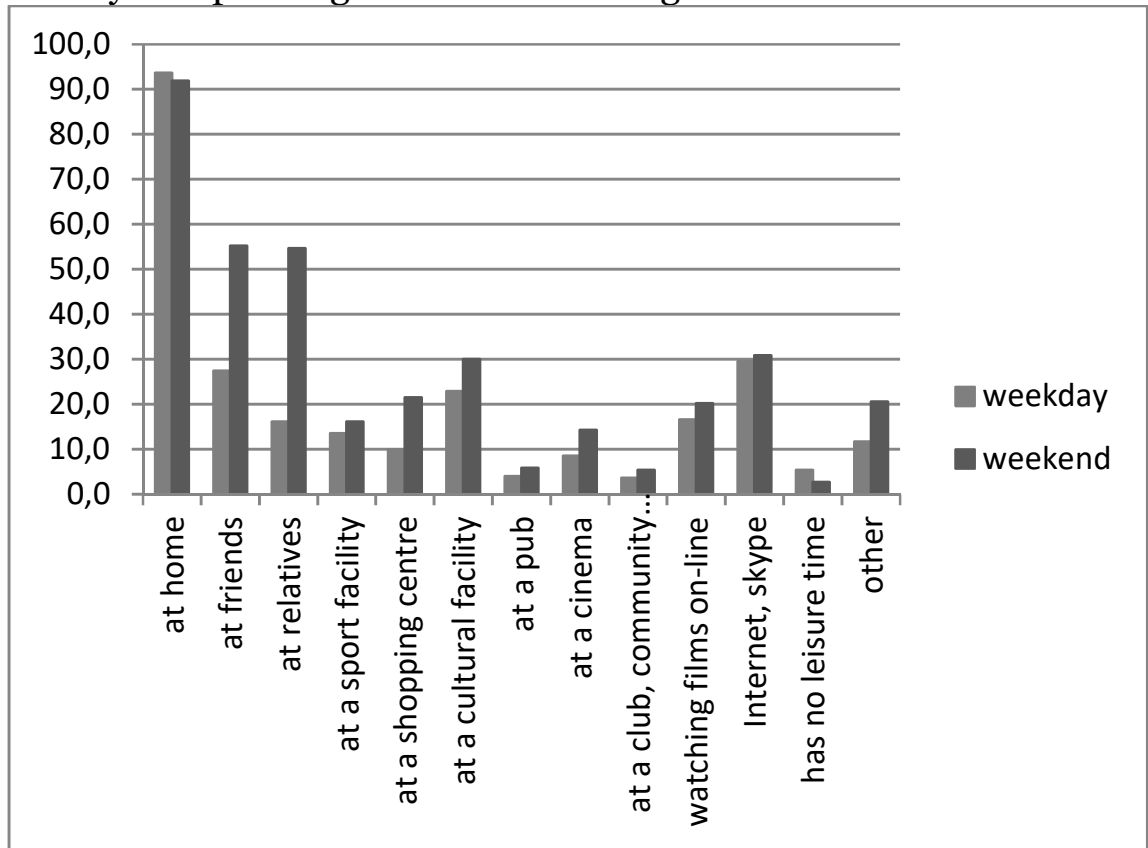

\section{Holiday}

During the last 3 years, as a leisure activity, almost half of university staff respondents spent their holidays inland three or more times, while spending holidays abroad characterised only one-third of them (Table 3). Approximately $40 \%$ of respondents had not been on a holiday abroad at all during the past 3 years.

Table 3. The frequency of spending holidays inland and abroad during the past 3

\begin{tabular}{|l|c|c|}
\hline \multicolumn{3}{|c|}{ years (\%) } \\
\hline Frequency & Inland\% & Abroad \% \\
\hline one time & 16.6 & 38.6 \\
\hline two times & 14.3 & 22.4 \\
\hline three or more times & 22.9 & 11.2 \\
\hline Total & 46.2 & 27.8 \\
\hline
\end{tabular}

Those, who were not participating in an inland holiday in the past 3 years reported almost in all cases no holiday abroad as well (Table 4). However, almost the half of those who had the opportunity to spend their holiday inland three or more times could go for a holiday abroad with a similar frequency as well (Table 4). 
Table 4. Number of holidays in the past 3 years (number of people)

\begin{tabular}{|c|c|c|c|c|c|c|}
\hline & & \multicolumn{5}{|c|}{ Number of foreign holidays in the past 3 years } \\
\hline & & none & one & two & $\begin{array}{c}\text { three or } \\
\text { more }\end{array}$ & total \\
\hline \multirow{5}{*}{ 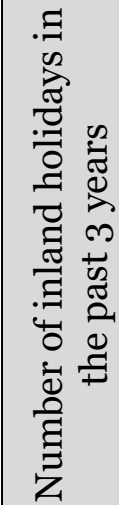 } & none & 26 & 5 & 2 & 4 & 37 \\
\hline & one & 16 & 8 & 3 & 5 & 32 \\
\hline & two & 20 & 19 & 5 & 7 & 51 \\
\hline & $\begin{array}{c}\text { three or } \\
\text { more }\end{array}$ & 24 & 18 & 15 & 46 & 103 \\
\hline & Total & 86 & 50 & 25 & 62 & 223 \\
\hline
\end{tabular}

\section{Participation in screening}

Women went to breast screening in every two years $(42.4 \%)$, or less (34.0\%), participation in cervix screening was mainly of yearly frequency (64.5\%). There was a considerable number of women who participated in cervix screening with less than a two years frequency (18.7\%). The male respondents generally went for prostate cancer screening with a less than two years frequency (84.9\%). The respondents participated in skin cancer (62.9\%) and mouth cancer (77.5\%) screenings less than every two years. However, there were respondents who went for a skin cancer screening in every year $(21.8 \%)$ or in every two years $(15.2 \%)$. In general, it was true, that women were more conscious about their own health than the male ones, and considered the importance of their health higher than their male co-workers. There were also significant differences between men and women concerning participation in colorectal screening $\left(\chi^{2}=8.54, p=0.04\right)$. Women participated mainly with a less than two years frequency, while men did the same with a similar frequency (91.4\%), and showed a yearly participation (3.5\%).

\section{Correlation study of health behaviour and subjective health status}

Respondents considered their own health status quite good on a scale of 5 $($ mean $=3.7, \mathrm{SD}=0.80)$. There was a considerable correlation between the subjective judgement of one's own health status and the extent he or she considered own health important (Table 5). Those, who were more satisfied with their fitness considered their health more important. Those respondents, who were more satisfied with their fitness, looks and health considered their own health status better than those less satisfied ones (Table 5). 
Table 5 . The correlation between satisfaction and health

\begin{tabular}{|l|c|c|}
\hline & $\begin{array}{c}\text { Importance of own } \\
\text { health }\end{array}$ & $\begin{array}{c}\text { Subjective opinion } \\
\text { about own health status }\end{array}$ \\
\hline Importance of own health & 1.00 & $\mathbf{0 . 2 6}$ \\
\hline $\begin{array}{l}\text { Subjective opinion about } \\
\text { own health status }\end{array}$ & $\mathbf{0 . 2 6}$ & 1.00 \\
\hline Satisfaction with own health & 0.23 & $\mathbf{0 . 7 0}$ \\
\hline Satisfaction with own fitness & 0.20 & $\mathbf{0 . 5 5}$ \\
\hline Satisfaction with looks & 0.23 & $\mathbf{0 . 4 6}$ \\
\hline
\end{tabular}

The table contains the Spearman rho values. Each data in the table indicate a significant correlation on level $p<0.01$.

Analysis of the connection between place of spending leisure time and own judgement of health status revealed, that those, who spent their leisure time in sport facilities $(t=3.56, p<0.01)$, or with friends $(t=3.06$, $\mathrm{p}<0.01)$ evaluated their health status higher than those who spent their leisure time at home or in shopping centres.

\section{Summary and conclusions}

Our research data revealed that health was very important for the employees of the University of Szeged, especially for women workers. With only a few exceptions they all had knowledge concerning health, health protection and healthy lifestyle. This knowledge they acquired out of interest or possessed due to their profession. Health knowledge and consciousness was also reflected in their actual health behaviour, providing an excellent example for their students.

Employees' health behaviour can also be an example, as the rate of smokers is low and alcohol consumption is also mild. It could also be highlighted, that the observed employees drink tap water and mineral water mainly, eat less fatty meat, do not use excessive salting and prefer mixed nutrition. They spend their free time usefully, with nurturing their social bonds, as well as with engaging in cultural and physical activities.

Some aspects of their nutrition, however, needs improvement. Such aspects are the right amount of eating during the day, the preference of whole grain bread to the white one, and the higher frequency of eating raw vegetables and fruits.

To sum all findings up, we can say that employees of the University of Szeged are concerned about their health and act for preserving and promoting it. They strive at creating a good well-being. Their health behaviour is acceptable and can mean a suitable example for the young adult generation.

By a slight increase in the currently small financial appreciation of the HE staffs a considerable improvement could be achieved in their nutrition habits, access to travelling for a holiday or in their leisure habits. 


\section{References}

Bourdieu, P. (1986). The forms of capital. In Richardson, J. (Ed.), Handbook of Theory and Research for the Sociology of Education (pp. 241-258). New York: Greenwood.

Fichtenberg, C. M., \& Glantz, S. A. (2006). Effect of smoke-free workplaces on smoking behaviour: systematic review. In Warner, K. E. (Ed.), Tobacco Control Policy (pp. 277-296). San Francisco: Jossey-Bass.

Filstad, C., Dean, G., Fahsing, I., \& Gottschalk, P. (2007). Newcomers' use of colleagues as role models: Research propositions for investigative thinking styles of law enforcement detectives: Knowledge and process management. The Journal of Corporate Transformation, 14 (2), 71-80.

Gardner, B. (2015). A review and analysis of the use of 'habit' in understanding, predicting and influencing health-related behaviour. Health Psychology Review, 9 (3), 277-295, DOI: 10.1080/17437199.2013.876238

Hong, H. (2009). Scale Development for Measuring Health Consciousness: Reconceptualization. In 12th Annual International Public Relations Research Conference. CoralGables, Florida: Holiday Inn University of Miami. Retrieved from http://www.instituteforpr.org/wpcontent/uploads/ScaleDvlpmentMeasuring.pdf [01.04.2016].

Hutchinson, A. D., \& Wilson, C. (2011). Improving nutrition and physical activity in the workplace: a meta-analysis of intervention studies. Health Promotion International, 27 (2), 238-249.

Kulhánová, I., Hoffmann, R., Judge, K., Looman, C. W. N., Eikemo, T. A., Bopp, M., Deboosere, P., Leinsalu, M., Martikainen, P., Rychtaríková, J., Wojtyniak, B., Menvielle, G., \& Mackenbach, J. P. (2014). Assessing the potential impact of increased participation in higher education on mortality: Evidence from 21 European populations. Social Science \& Medicine, 117, 142-149.

Kouvonen, A., Kivimäki, M., Virtanen, M., Pentti, J., \& Vahtera, J. (2005). Work stress, smoking status and smoking intensity: an observational study of 46.190 employees. Journal of Epidemiology \& Community Health, 59 (1), 63-69.

Li, J., \& Powdthavee, N. (2015). Does more education lead to better health habits? Evidence from the school reforms in Australia. Social Science \& Medicine, 127, 83-91.

Linder, M. (2009). Analysis of Higher Education Employee Exercise Behaviors. Open Access Theses and Dissertations from the College of Education and Human Sciences, Paper No. 55. Retrieved from http://digitalcommons.unl.edu/cgi/viewcontent.cgi?article $=1054 \&$ context $=$ ce hsdiss [29.07.2015].

Lindström, M., Hanson, B. S., \& Östergren, P. (2001). Socioeconomic differences in leisure-time physical activity: the role of social participation and social capital in shaping health related behaviour. Social Science \& Medicine, 52 (3), 441-451.

Lumpkin, A. (2008). Teachers and Role Models Teaching Character and Moral Virtues. Journal of Physical Education, Recreation \& Dance, 79 (2), 45-49.

Mátó, V., Nagymajtényi, L., \& Paulik, E. (2015). Szegedi Tudományegyetemen a pedagógusképzésben dolgozók munkakörülményei és egészségi állapota. Módszertani Közlemények, 55 (4), 25-35.

Nieminen, T. (2015). Healthier Together? Social capital, Health behaviour and Health. [Academic Dissertation]. Helsinki: Unigrafia. Retrieved from https://helda.helsinki.fi/bitstream/handle/10138/15389o/healthie.pdf?seque nce $=1$ [02.08.2015]. 
Paice, E., Heard, S., \& Moss, F. (2005). How important are role models in making good doctors? British Medical Journal, 325, 707-710.

Perry, G. M., \& Nixon, C. J. (2005). The influence of role models on negotiation ethics of college students. Journal of Business Ethic, 62 (1), 25-40.

Ross, C. E., \& Wu, C. (1995). The links between education and health. American Sociological Review, 60 (5), 719-745.

Sparks, K., Faragher, B., \& Cooper, C. L. (2001). Well-being and occupational health inthe 21st century workplace. Journal of Occupational and Organizational Psychology, 74 (4), 489-509. 